

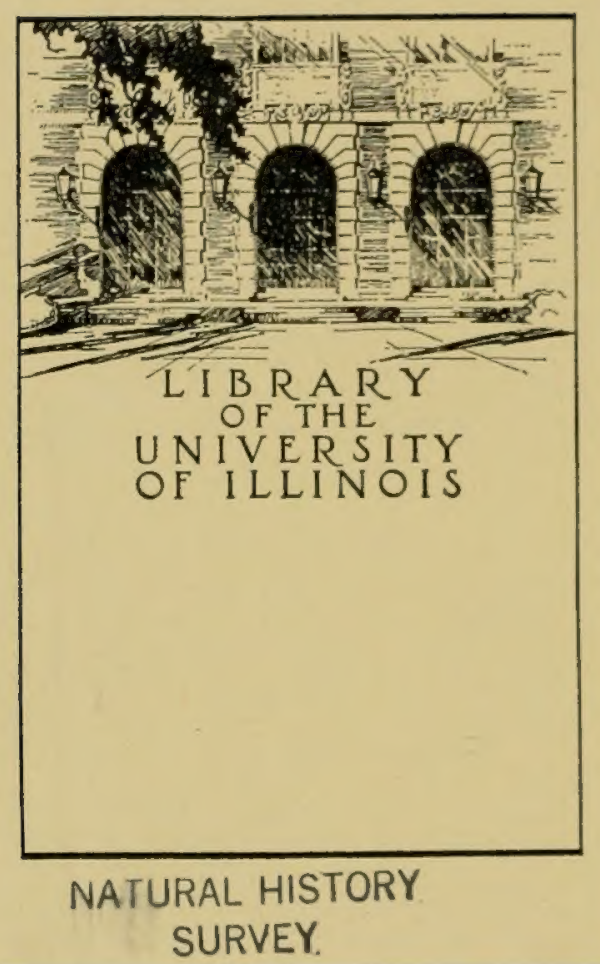







\section{CONTROL OF ELM DISEASES}

IN

NURSERY ELM PLANTINGS

$$
\text { J. C. Carter }
$$

$$
\begin{gathered}
\text { STATE OF ILLINOIS } \\
\text { Henry Horner, Governor } \\
\text { Department of Registration and Education } \\
\text { NATURAL HISTORY SURVEY DIVISION } \\
\text { Theodore H. Frison, Chief }
\end{gathered}
$$

Biological Notes No. 7

Contribution from the

Section of Applied Botany and Plant Pathology

Leo R. Tehon, Botanist

(Publication No. 305) 


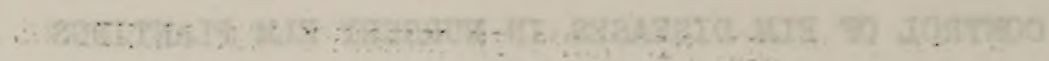

$$
\begin{aligned}
& \cdots+2 \times y+1
\end{aligned}
$$

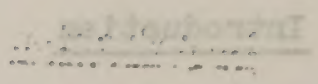

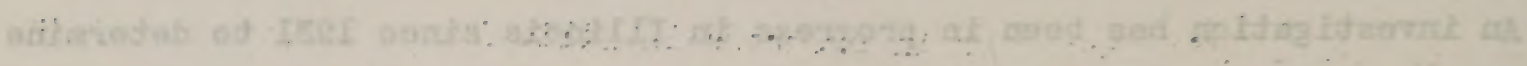

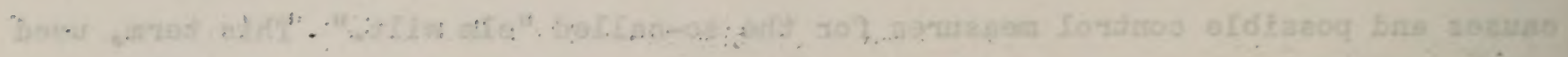

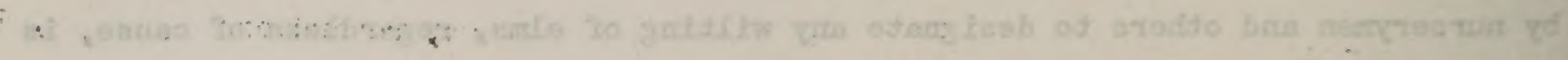

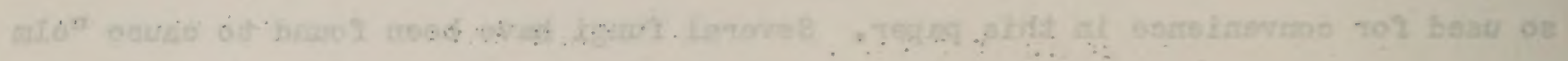

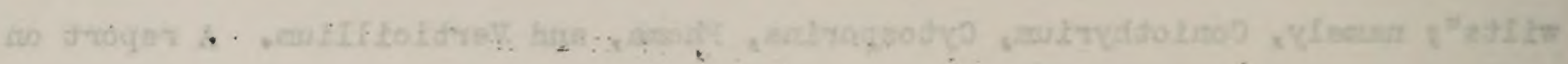

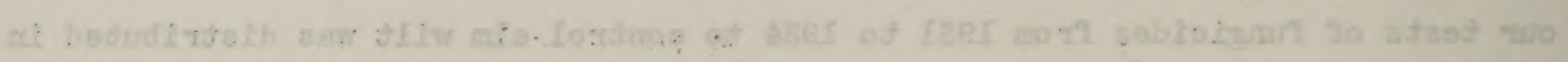

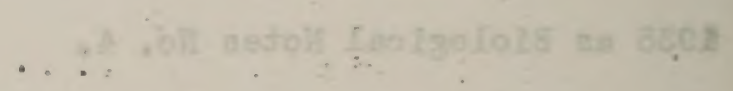

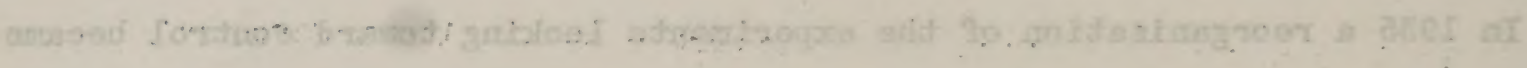

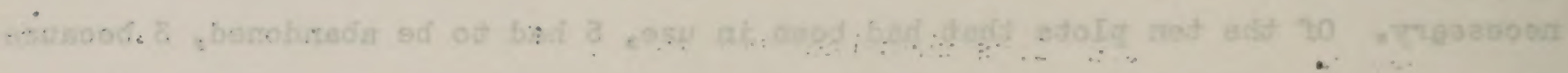

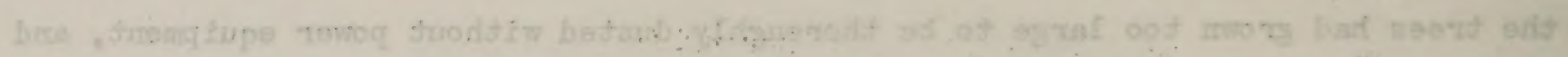

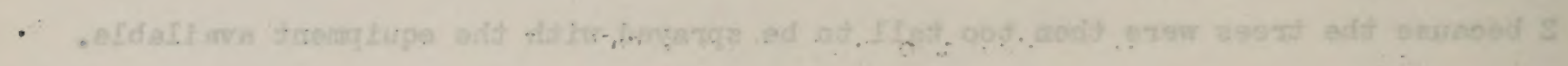

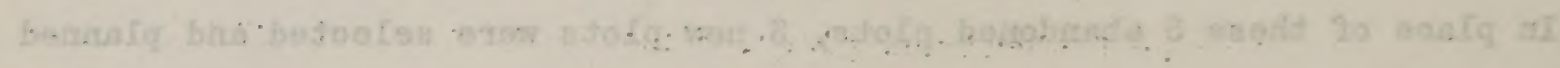

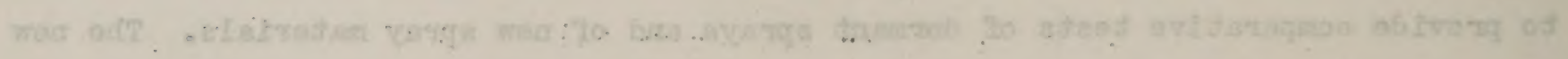

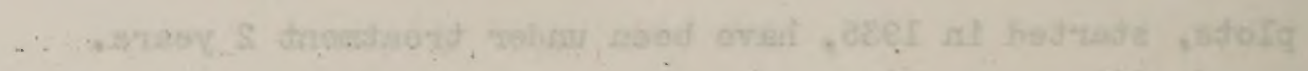

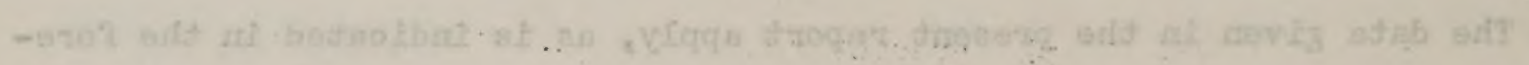

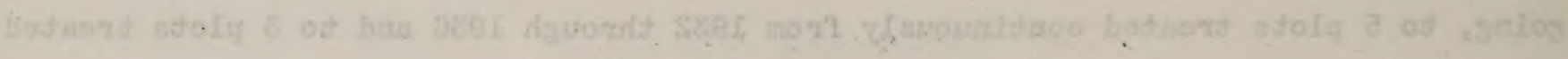

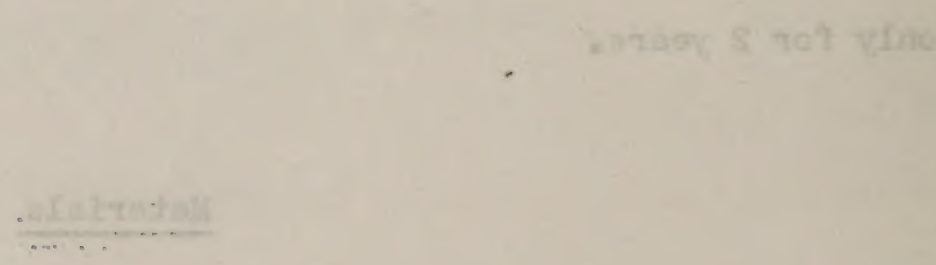

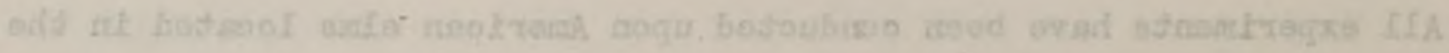

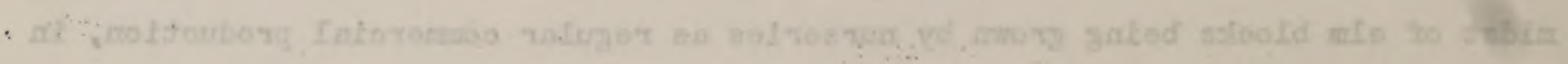


cooperation with nursery owners. Both dormant and summer sprays and dusts have been used. For the entire period 1932-1936 one copper fungicide (Corona Bordeaux) and four sulphur fungicides (Koloform, Kolodust, flotation sulphur dust, and dry wettable flotation sulphur) have been used continuously on the same trees as summer sprays. In 1935 tests were begun with two new copper fungicides (Instant Bordeaux and "Z-0") and one new sulphur fungicide (liquid lime sulphur). Instant Bordeaux and "Z-O" have been used both for dormant and for summer sprays. Liquid lime sulphur has been applied only as a dormant spray and has been followed by summer applications of Koloform and dry wettable flotation sulphur. These fungicides may be described as follows:

\section{A. Copper fungicides.}

1. Corona Bordeaux is a commercial, pre-mixed Bordeaux that only needs to be mixed with proper amounts of water to obtain required strengths. This fungicide, manufactured by the Corona Chemical Division of the Pittsburg Plate Glass Company, is composed of active ingredient (copper) of not less than 13 percent and inert ingredients of not more than 87 percent.

2. Instant Bordeaux is a recently developed Bordeaux that can be made very quickly and easily as needed by mixing blue vitriol (copper sulphate) powder and superfine hydrated lime with water in proper proportions. To prepare 100 galIons of 4-4-50 Instant Bordeaux, weigh out 8 pounds of powdered copper sulphate and 8 pounds of superfine hydrated lime. Begin filling the spray tank with water. When the tank is approximately one-fourth full, start the engine and keep it running until the tank is full. As soon as the engine is started, place the copper sulphate upon the intake strainer and wash it into the tank. When the tank is three-fourths full, place the superfine hydrated lime on the intake strainer and wash it into the tank. 


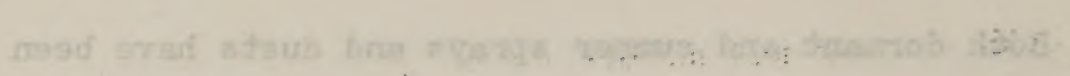

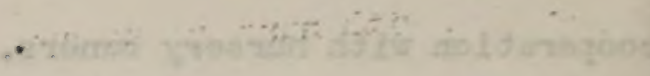

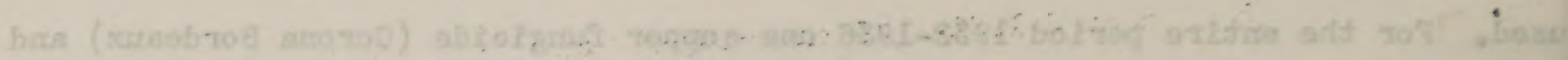

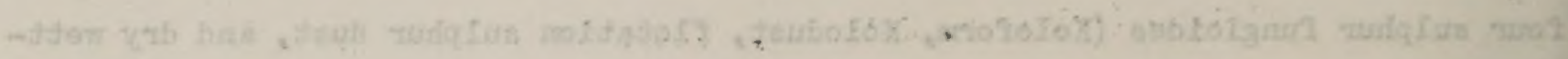
anduata

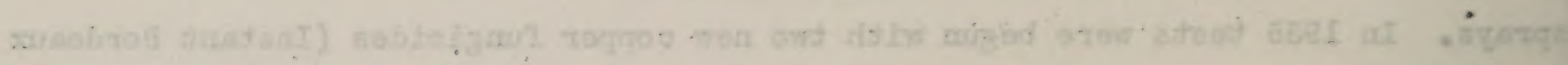

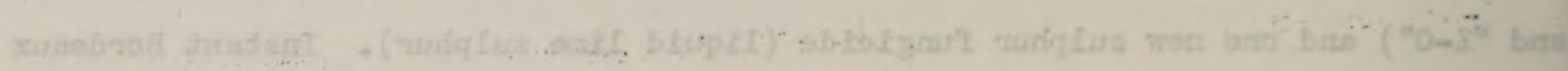

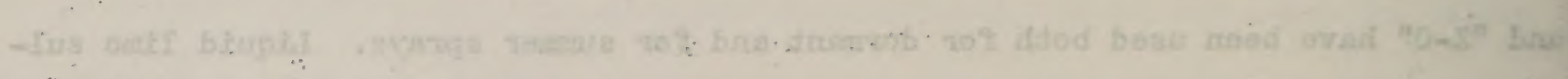

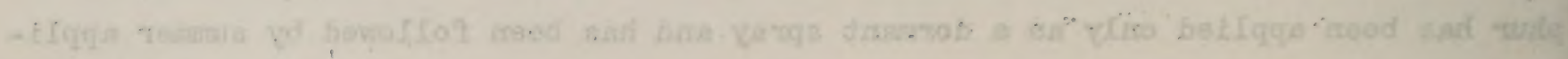

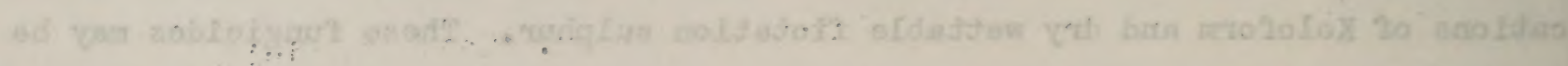
asmoiffon an bodtrozab

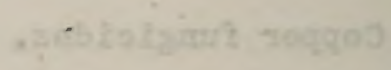

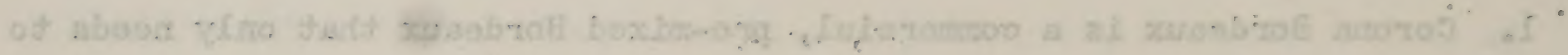

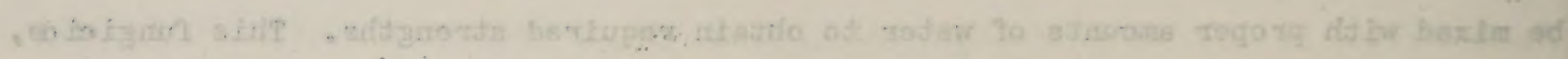

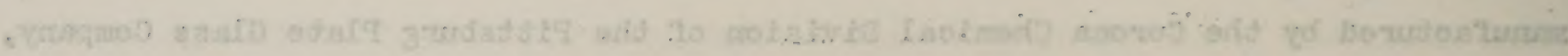

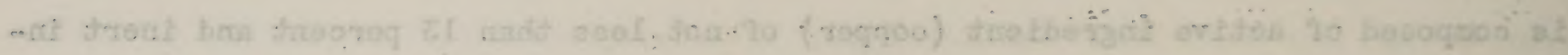
the.

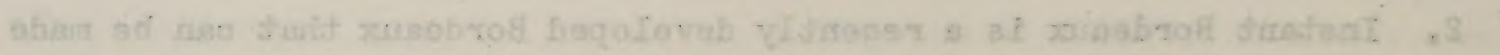

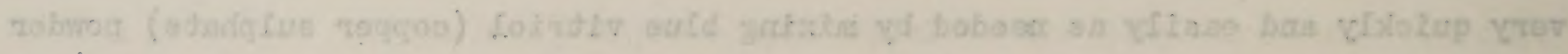

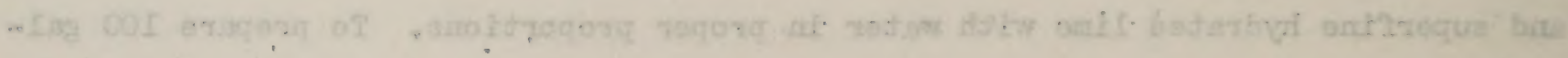

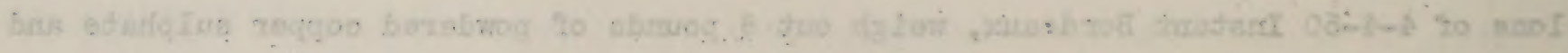

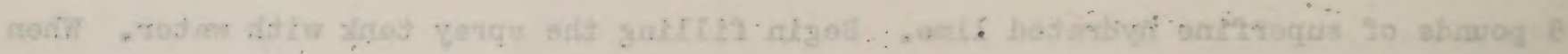

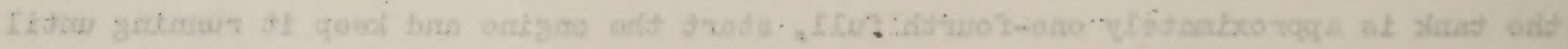

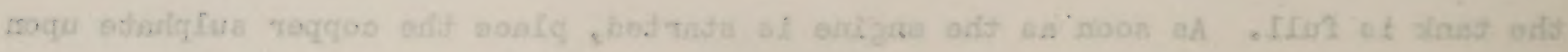

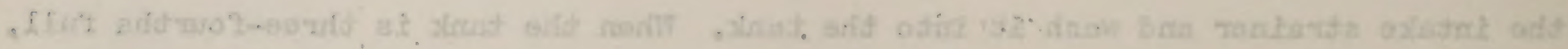

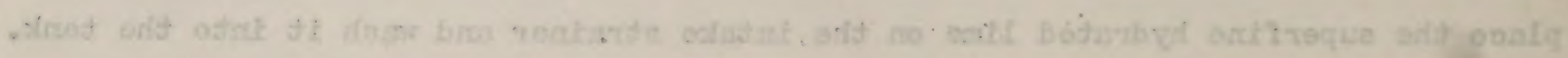


Let the agitator run for approximately 1 minute after the tank is full. Instant Bordeaux is then ready to use. In general, Instant Bordeaux settles out more slowly than commercially prepared Bordeaux mixtures.

3. "Z-O," which is manufactured by the Nichols Copper Company, is a copper fungicide which contains copper equivalent to 26 percent in metallic form. It has been developed as a substitute for the Bordeaux mixture used on apples and has been found practical for general spraying of omamentals. It can be used in dust form for truck crops. There is a gradual release of copper from "Z-0," which, it is claimed, makes it less harmful to treated plants than any other copper fungicides.

\section{B. Sulphur sprays.}

1. Liquid lime sulphur is a standard fungicide used in orchard practice. We have used it only as a dormant spray, at the strength of 1 to 10 ( 1 part liquid lime sulphur to 10 parts water). The fall dormant was applied in October or November and the spring dormant in March or early April.

2. Koloform is a sulphur dust, sold by the Niagara Spray and Chemical Company, which forms a spray when added to water. It is composed of active ingredient (sulphur) of not less than 54 percent and inert ingredients of not more than 46 percent.

3. Koppers Flotation Sulphur, manufactured by the White Tar Company of liew Jersey, Inc., is an exceedingly fine sulphur dust which mixes readily with water and is used as a spray. It is composed of active ingredient (sulphur) of not less than 80 percent and inert ingredients of not more than 20 percent.

C. Sulphur dusts.

1. Kolodust, manufactured by the Niagara Spray and Chemical Company, is 

very similar to Koloform but is applied as a dust. It is composed of active ingredient (sulphur) of not less than 87 percent and inert ingredients of not more than 13 percent. A portion of the sulphur in Kolodust and also in Koloform consists of highly colloidal sulphur produced by the adsorption of molten sulphur into Bentonite clay.

2. Koppers Flotation Sulphur Dust is similar to Koppers Flotation Sulphur but is used as a dust.

\section{Methods}

The trees received three types of treatment, and ample provision mas made for maintaining untreated trees as checks against the treatments. The types of treatment were as follows:

1. Pruning: Diseased parts of infected trees in test blocks were pruned out and destroyed.

2. Fungicides: Trees in test blocks were sprayed or dusted with the proper fungicides.

3. Pruning plus fungicides: Diseased parts of infected trees in test blocks were pruned out and destroyed. After that, the trees in such blocks were sprayed or dusted with the proper fungicides.

From the beginning of the work in 1932 until the fall of 1935, applications of the liquid fungicides were made with the sprayers owned by the nurserymen at each place where a plot of trees was located. These spravers varied from 50gallon hand operated outfits to 100-gallon power outfits. But since the fall of 1935 all spraying has been done with a 100-gallon Bean Little Giant Duplex outfit. 

The various capacities and types of outfits used at first naturally resulted in lack of uniformity of spray application in the different plots, but since 1935 this difficulty has not existed.

Sulphur dusts were applied with a Niagara blower dust gun. This gun blows a good cloud of dust to a height of 8 to 10 feet. Almost without exception, the dust applications were made in early morning when dew was on the foliage and before the wind became too strong to prevent uniform dusting.

Summer applications of fungicides have been started in lay or early June each year, except in 1936 when the first summer spray was applied during the last wreek of April. In the early period of the work, applications were made at approximately three-week intervals. More recently, the first summer spray has been applied in early May and subsequent applications have been made every ten days to two weeks until the beginning of the dry weather period, which is usually about the middle of July. Three-week intervals between applications have been allowed after that time. Summer applications of fungicides were terminated the latter part of August.

Dormant applications of liquid fungicides were started in the spring of 1935 in 2 of the 3 new plots started that year. The practice of applying both spring and fall dormants has been followed, the fall dormant being applied in October or INovember and the spring dormant in Harch or early April before the buds opened.

Observations were made on the effectiveness of each funficide used and on each type of practice cmployed. Data were recorded nt refular intervals during the growing season on the prevalence of the "clm wilt." The trees in the several plots were divided into separate blocks and each block in a given plot received a different treatment. One block of trees in each plot remained untreated, and these served as a check on the various treatments employed. 

Five-year Tests with Summer Treatments

The data presented in table 1 summarize the results of five years of experiment with pruning and with Bordeaux mixture (Corona), Koppers flotation sulphur, Koloform, and Kolodust.

Table 1.--Results in disease control in nursery elms obtained from 5 consecutive seasons of pruning, spraying, dusting, and pruning combined with spraying or dusting.

\begin{tabular}{|c|c|c|c|c|}
\hline $\begin{array}{l}\text { Plot numbers } \\
\text { and } \\
\text { treatments used }\end{array}$ & $\begin{array}{c}\text { No. of trees } \\
\text { originally } \\
\text { present }\end{array}$ & $\begin{array}{l}\text { Io. of trees } \\
\text { contracting } \\
\text { disease in } \\
5 \text { years }\end{array}$ & $\begin{array}{l}\text { Difference in } \\
\text { favor of }(+) \text { or } \\
\text { against }(-) \\
\text { treatment }\end{array}$ & $\begin{array}{l}\text { Percentage of } \\
\text { control }(+) \\
\text { or lack of } \\
\text { control }(-) * \\
\end{array}$ \\
\hline \multicolumn{5}{|l|}{ Plot III } \\
\hline Check & 300 & 33 & & \\
\hline Pruning & 300 & 7 & +26 & +78.8 \\
\hline Bordequx spray & 300 & 38 & -5 & -15.2 \\
\hline Bordeaux + pruning & 300 & 29 & +4 & +12.1 \\
\hline \multicolumn{5}{|l|}{ Plot IV } \\
\hline Check & 500 & 7 & & \\
\hline Pruning & 500 & 6 & +1 & +14.3 \\
\hline Koloform spray & 500 & 9 & -2 & -28.6 \\
\hline Koloform + pruning & 500 & 13 & -6 & -85.7 \\
\hline \multicolumn{5}{|l|}{ Plot VII } \\
\hline Check & 711 & 151 & & \\
\hline Bordeaux spray & 474 & 113 & $-18 * *$ & -11.9 \\
\hline spray & 474 & 116 & $-23 * *$ & -15.2 \\
\hline \multicolumn{5}{|l|}{ Plot VIII } \\
\hline Check & 400 & 64 & & \\
\hline Pruning & 400 & 67 & -3 & -5.0 \\
\hline Kolodust & 400 & 46 & +18 & +28.1 \\
\hline Kolodust + pruning & 400 & 33 & +31 & +50.0 \\
\hline \multicolumn{5}{|l|}{ PIot IX-I } \\
\hline Check & 347 & 113 & & \\
\hline Koloform spray & 347 & 142 & -29 & -25.7 \\
\hline
\end{tabular}



Pruning out diseased parts, when done without any other treatment, gave 79 percent control in plot III and I4 percent in plot IV, but failed by 5 percent in plot VIII.

A greater number of cases of wilt occurred in the blocks of sprayed trees than in the checks. Bordeauz in plot III permitted the occurrence of 15 percent more, and in plot VII 12 percent more diseased trees than occurred in the corresponding checks. With Koloform in plot IV, the number of diseased trees was 28 percent greater, and in plot IX-L 26 percent greater than occurred in the check blocks. And in the flotation sulphur block in plot VII the proportion of diseased trees was greater by 15 percent than in the check. In contrast, however, sulphur dust proved somewhat effective, Kolodust permitting the occurrence in plot VIII of 28 percent fewer cases of wilt than occurred in the check.

Results obtained when pruning was combined with fungicides proved erratic. In plot III, combined with Bordeaux, trees becoming infected were 12 percent fewer than in the check and about 24 percent fewer than with Bordeaux alone. But combined with Koloform in plot VII, pruning appears to have increased very considerably the proportion of diseased trees, in comparison with both the check and the sprayed blocks. Done in combination with dusting---Kolodust in plot VIII---it appears to have been moderately effective, the number of diseased trees being but 50 percent of the number occurring in the chock block, 70 percent of the number in the dusted block, and 49 percent fewer than when pruning alone was done.

These five years of consecutive treatment indicate, on the basis of tho results just stated, that so far as "wilt" control is concerned the use of Bordeaux and sulphur sprays for summer application alone tends to increase the prevalence of "elm wilt." The practico of pruning out discased parts gencrally tends to reduce 

the amount of disease, and the general effect of combined pruning and spraying is a decrease in the effectiveness of pruning which tends to balance the ineffectiveness of sprays. Dusting with sulphur is, however, somewhat effective and, when combined with pruning, proves the most effective among the treatments tested.

\section{Tests with Sulphur Summer Spray and Dusts}

Data in addition to those obtained from the uniform 5-year long treatments just described are furnished by plots IX-S and XIV for a sulphur spray and 2 sulphur dusts. These are summarized in table 2.

Table 2.--"Wilt" control obtained from treatment of nursery elms by pruning, by spraying and by dusting with sulphur, and by combining pruning with spraying and with dusting for various periods.

\begin{tabular}{|c|c|c|c|c|}
\hline $\begin{array}{l}\text { Plot numbers } \\
\text { and } \\
\text { treatments used }\end{array}$ & $\begin{array}{l}\text { No. of trees } \\
\text { originally } \\
\text { present }\end{array}$ & $\begin{array}{l}\text { No. of trees } \\
\text { contracting } \\
\text { disease }\end{array}$ & $\begin{array}{l}\text { Difference in } \\
\text { favor of }(+) \text { or } \\
\text { against }(-) \\
\text { treatment* }\end{array}$ & $\begin{array}{l}\text { Percentage of } \\
\text { control (t) } \\
\text { or lack of } \\
\text { control (-) }\end{array}$ \\
\hline \multicolumn{5}{|l|}{ Plot IX-S (sprays) } \\
\hline Check, 5 seasons & 226 & 74 & & \\
\hline Pruning, 5 seasons & 250 & 62 & +20 & +24.4 \\
\hline Koloform, 5 seasons & 217 & 47 & +28 & +34.1 \\
\hline $\begin{array}{l}\text { Koloform, } 5 \text { seasons } \\
+ \text { pruning, } 2 \text { seasons }\end{array}$ & 200 & 44 & +27 & +32.9 \\
\hline \multicolumn{5}{|c|}{ Plot XIV (dusts, 2 seasons) } \\
\hline Check & 236 & 84 & & \\
\hline Pruning & 218 & 46 & +37 & +41.1 \\
\hline $\begin{array}{l}\text { Flotation sulphur } \\
\text { Flotation sulphur }\end{array}$ & 253 & 86 & +4 & +4.4 \\
\hline+ pruning & 222 & 28 & +58 & +64.4 \\
\hline Kolodust & 235 & 81 & +3 & +3.3 \\
\hline Kolodust + pruning & 201 & 53 & +23 & +25.6 \\
\hline
\end{tabular}

* Calculated on the basis of 250 trees per block in plot IX-S and 253 trees per block in plot XIV. 

Plot IX-S has been in oporation for 5 years and the data for the check, pruning, and Koloform sprayed blocks cover the entire period. Pruninf in addition to Koloform has been done for 2 years only. The most prevalent elm disease in this plot is the Coniothyrium canker. Pruning during 5 years proved about 25 percent effective and holoform spray about 35 percent effective. The pruning of a group of the sprayed trees during the past 2 years has not materially affected the value of the spray.

Plot XIV, in progress for 2 years, provides a test of the effectiveness of sulphur dusts in the control chiefly of Phoma dieback. Neither flotation sulphur dust nor Kolodust give noteworthy control, but pruning appears to have been about 40 percent effective. With pruning and flotation sulphur combined a large increase over the effectiveness of each appears demonstrated in nearly 65 percent control. But with Kolodust and pruning combined, the 25 percent control obtained is less than that show for pruning alone.

\section{Two-year Tests of Dormant and Summer Sulphur Sprays}

The possibility of increasing the effectiveness of sulphur sprays by supplementing them with dormant season sprays has been under test for 2 years. In plot XII, consisting of 850 trees, combinations of liquid lime sulphur as the dormant spray and dry wettable flotation sulphur and Koloform as summer sprays have given the data shown in table 3 .

Outstanding is the fact that the addition of lime sulphur as a dormant spray has not tended to increase the effectiveness of summer sulphur sprays, and in this plot it is important to note that pruning, whether used alone or in combination with sprays, has tended very decidedly to increase the proportion of diseased trees. 

Table 3.-milt" control obtained from 2 years' treatment of nursery elms with liquid lime sulphur as a dormant spray and with sulphur as summer sprays.

\begin{tabular}{|c|c|c|c|c|}
\hline $\begin{array}{l}\text { Plot numbers } \\
\text { and } \\
\text { treatments used }\end{array}$ & $\begin{array}{l}\text { No. of trees } \\
\text { originally } \\
\text { present }\end{array}$ & $\begin{array}{l}\text { No. of trees } \\
\text { contracting } \\
\text { disease }\end{array}$ & $\begin{array}{c}\text { Difference in } \\
\text { favor of }(+) \text { or } \\
\text { against }(-) \\
\text { treatment* }\end{array}$ & $\begin{array}{l}\text { Percentage of } \\
\text { control (+) } \\
\text { or lack of } \\
\text { control ( })\end{array}$ \\
\hline \multicolumn{5}{|l|}{ Plot XII (sprays) } \\
\hline Check & 134 & 21 & & \\
\hline Pruning & 145 & 35 & -12 & -52.2 \\
\hline $\begin{array}{l}\text { Dormant and flotation } \\
\text { sulphur summer spray }\end{array}$ & 142 & 26 & -4 & -17.4 \\
\hline $\begin{array}{l}\text { Dormant, flotation } \\
\text { sulphur + pruning }\end{array}$ & 142 & 41 & -19 & -82.6 \\
\hline $\begin{array}{l}\text { Dormant and Koloform } \\
\text { summer spray }\end{array}$ & 146 & 25 & -2 & -8.7 \\
\hline $\begin{array}{l}\text { Dormant, Koloform } \\
+ \text { pruning }\end{array}$ & 141 & 26 & -4 & -17.4 \\
\hline
\end{tabular}

*Calculated on a basis of 146 trees per block.

\section{Two-year Tests of Dormant and Summer Copper Sprays}

Combined dormant and summer treatment with fungicides in which copper is the active ingredient have been attempted, in spite of the apparent ineffectiveness of commercial Bordeaux as a summer spray. In plot XII tests of "z-0" (see p. 3), and in plot XIII tests of Instant Bordeaux (see p. 2), have been under way for 2 years. The data taken up to the present in these plots are summarized, with present indications, in table 4.

The value of both " $\mathrm{Z}-\mathrm{O}$ " and Instant Bordeaux is much in doubt, the data being inconclusive. When used alone they have permitted moro trees to become diseased than occurrod in the untreated chocks, but when combinod with pruning, shown to operate unfavorably in both plots, the outcome is equivalent to no treatment at all for " $\mathrm{Z}-\mathrm{O}$ " and 32 percent control for Instant Bordcaux. 

Table 4.-."Wilt" control obtained from 2 years' treatment of nuxsery elms with dormant and summer copper sprays.

\begin{tabular}{|c|c|c|c|c|}
\hline $\begin{array}{l}\text { Plot numbers } \\
\text { and } \\
\text { treatments used } \\
\end{array}$ & $\begin{array}{c}\text { No. of trees } \\
\text { originally } \\
\text { present }\end{array}$ & $\begin{array}{l}\text { No. of trees } \\
\text { contracting } \\
\text { disease }\end{array}$ & $\begin{array}{l}\text { Difference in } \\
\text { favor of }(+) \text { or } \\
\text { against }(-) \\
\text { treatment* }\end{array}$ & $\begin{array}{c}\text { Percentage of } \\
\text { control (+) } \\
\text { or lack of } \\
\text { control ( }(-)\end{array}$ \\
\hline \multicolumn{5}{|l|}{ PIot XII } \\
\hline Check & 134 & 21 & 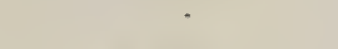 & ". \\
\hline Pruning & 145 & 35 & -12 & -52.2 \\
\hline $\mathrm{Z}-\mathrm{O}$ & 143 & 28 & -5 & -21.7 \\
\hline Z-0 + pruning & 133 & 21 & 0 & 0.0 \\
\hline \multicolumn{5}{|l|}{ PIot XIII } \\
\hline Check & 186 & 37 & & \\
\hline Pruning & 181 & 40 & -4 & -10.8 \\
\hline Instant Bordeaux & 178 & 54 & -19 & -51.4 \\
\hline Instant Bordeaux & & & & \\
\hline + pruning & 186 & 25 & +12 & +32.4 \\
\hline
\end{tabular}

*Calculated on the basis of 145 trees per block in plot XII and 186 trees per block in plot XIII.

\section{Results}

The foregoing tables and text have given detailed data derived from practical tests, conducted under actual nursery conditions, of a number of fungicides as preventives of "elm wilt." Other considerations, such as effect of treatment on growth, general health, survival, or value, have been ignored. A tree, once it became diseased, was counted out permanently, whether eventually it lived or died. Consequently the information presented deals solely with the effect of treatment upon new infection.

Because "elm wilt" is a collection of diseases, one of which may predominate in one situation or in one vear and another elsewhere or in another jear, experiments have becn scattered among sclected trec plots located at some distunce from each other. This has provided opportunity for fairer tests of treatmonts and 

Table 5.--Recapitulation of data on the effectiveness of treatments in preventing the occurrence of "wilt" diseases in nursery elms.

\begin{tabular}{|c|c|c|c|c|c|}
\hline \multirow[t]{2}{*}{ Treatment } & \multirow{2}{*}{$\begin{array}{c}\text { No. of blocks } \\
\text { of test trees } \\
\text { used }\end{array}$} & \multirow{2}{*}{$\begin{array}{l}\text { Total number } \\
\text { of trees in } \\
\text { test blocks }\end{array}$} & \multicolumn{3}{|c|}{$\begin{array}{l}\text { Percentage of control (+) } \\
\text { or lack of control ( }(-)\end{array}$} \\
\hline & & & Least & Greatest & Average* \\
\hline Pruning & 7 & 1994 & -52.2 & +78.8 & +17.2 \\
\hline \multicolumn{6}{|l|}{ Copper sprays } \\
\hline $\begin{array}{l}\text { Commercial Bor deaux } \\
\text { Commercial Bor deaux }\end{array}$ & 2 & 774 & -15.2 & -11.9 & -13.2 \\
\hline+ pruning & 1 & 300 & $-\infty$ & +12.1 & +12.1 \\
\hline $\begin{array}{l}\text { Instant Bordeaux } \\
\text { Instant Bordeaux }\end{array}$ & 1 & 178 & -51.4 & - & -51.4 \\
\hline + pruning & 1 & 186 & $-\infty$ & +32.4 & +32.4 \\
\hline $\mathrm{Z}-\mathrm{O}$ & 1 & 143 & -21.7 & - & -21.7 \\
\hline $\mathrm{Z}-0+$ pruning & 1 & 133 & -- & 0.0 & 0.0 \\
\hline \multicolumn{6}{|l|}{ Sulphur sprays } \\
\hline Flotation sulphur & 1 & 474 & -15.2 & -- & -15.2 \\
\hline Koloform & 3 & 1066 & -28.2 & +34.1 & -14.8 \\
\hline $\begin{array}{l}\text { Koloform + pruning } \\
\text { Lime sulphur and }\end{array}$ & 2 & 700 & -85.7 & +32.9 & -51.8 \\
\hline sulphur sprays & 2 & 288 & -17.4 & -8.7 & -13.0 \\
\hline $\begin{array}{l}\text { Lime sulphur and } \\
\text { sulphur sprays }\end{array}$ & & & & & \\
\hline + pruning & 2 & 283 & -82.6 & -17.4 & -50.1 \\
\hline \multicolumn{6}{|l|}{ Sulphur dusts } \\
\hline $\begin{array}{l}\text { Flotation sulphur } \\
\text { Flotation sulphur }\end{array}$ & 1 & 253 & $-\infty$ & +4.4 & +4.4 \\
\hline+ pruning & 1 & 222 & $-\infty$ & +64.4 & +64.4 \\
\hline Kolodust & 2 & 635 & +3.3 & +28.1 & +18.9 \\
\hline Kolodust + pruning & 2 & 601 & +25.6 & +50.0 & +41.8 \\
\hline
\end{tabular}

* This average is obtained by weighting data from individual blocks in proportion to the number of trees in the blocks.

has permitted the performance of certain tests in more than one locality. Since any treatment recommended as effective should prove itself to be so in any locality, the data from individual plots should be considered from that point of view.

A recapitulation of the essential data furnished by the plot tests is given in table 5. Both the number of plots in which each treatment was tried and 

the total number of trees upon which it was tested are Eiven, as are also the least and greatest degrees of prevention obtained. In determining average effectiveness, plot data have been weighted, whenever possible, in terms of the number of trees in the tree blocks concerned. In such cases the indexes of average control given in the table are considered to be more fairly expressive of the values of the treatments.

A casual inspection of table 5 will leave 3 outstanding impressions; namely, that more than half of the treatments appear to have no value, that not all the treatments that do have value give consistently positive results, and that the degree of effectiveness demonstrated by effective treatments often is disappointingly low. However, certain treatments negative as to their averages, have positive value under some conditions, and a few of the effective treatments have positive averages sufficiently high to indicate definite, practical usefulness.

A visual comparison, based on the averages given in table 5, of the effectiveness of tested treatments is show in figure 1, in which bars reaching to the right represent effective and bars reaching to the left ineffective treatment, the length of the bars representing the percentage of control or lack of control.

By cxamining this diagram it maj be seen that those treatments for which effectiveness has been demonstrated include (1) pruning, (2) copper sprays supplemented by pruning, (3) sulphur dusts, and (4) sulphur dusts supplemented by pruning. Those demonstrated to be ineffective include (1) copper sprays, (2) sulphur sprays, and (3) sulphur sprays supplemented by pruning.

A definite basis appears to have been demonstrated for judging the effectiveness of any treatment. It will be noted that all the treatments extending on the positive side in fisure I involve either pruning or dusting and that, without 



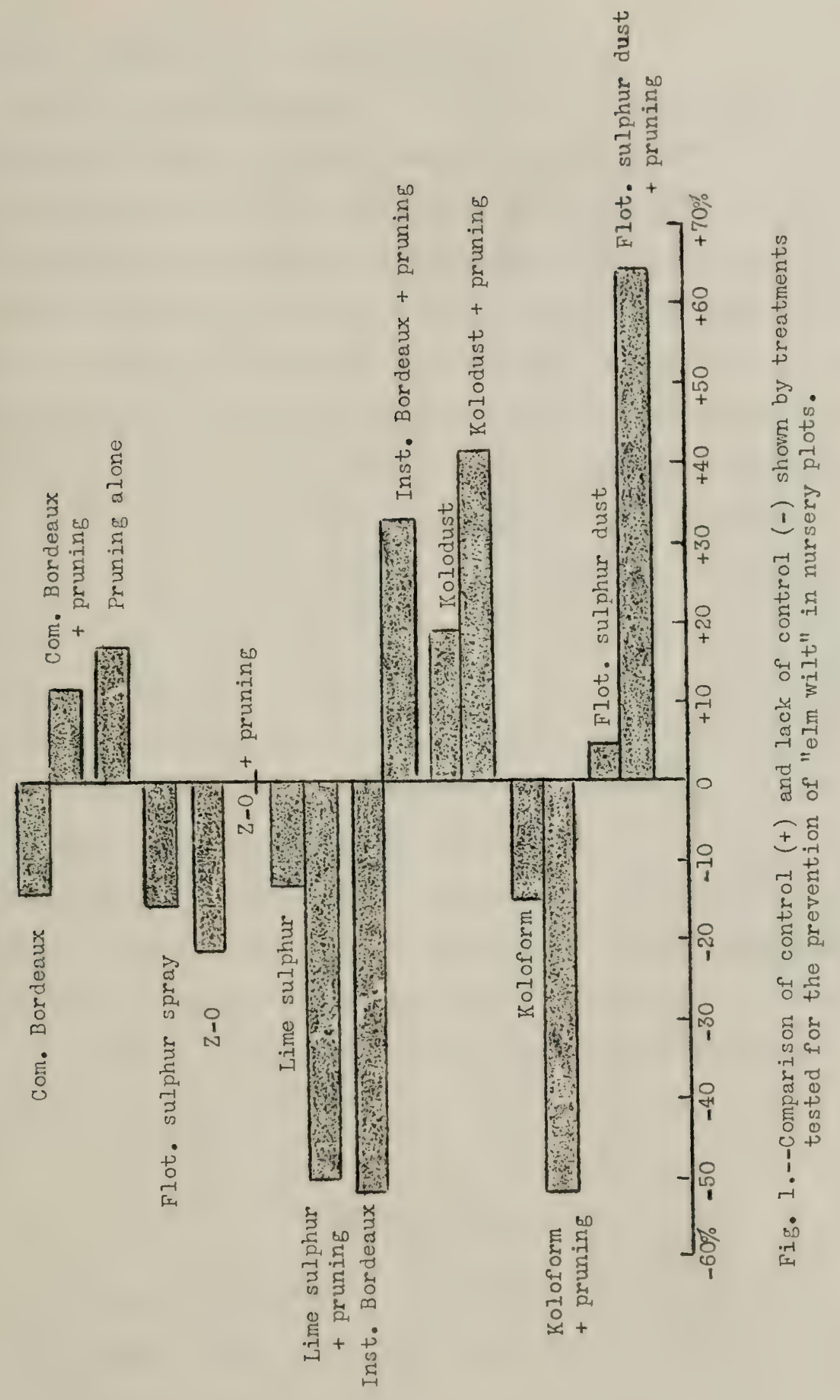



exception, those extending on the negative side are sprays.

The role played by pruning as a supplement to other treatments appears to be very important. Although not always dependable and as an average very moderately effective by itself (see table 5), pruning has a fairly consistent beneficial effect. It tends to increase the effectiveness of treatments which are themselves effective, as is the case with Kolodust and flotation sulphur dust, and it tends to lend value to treatments in themselves ineffective, as in the case of commercial Bordeaux and instant Bordeaux sprays. On the other hand, when used to supplement sulphur sprays it has increased greatly the ineffectiveness of these apparently ineffective sprays. Commercial Bordeaux mixture and pruning, as a unit of treatment, is not sufficiently effective to justify its use merely for disease prevention, and the same may be said of pruning when used alone. Instant Bordeaux mixture, when combined with pruning, holds considerable promise but needs more adequate testing. Both Kolodust and flotation sulphur dust are effective to a small degree when used alone, and in both cases this inherent effectiveness is increased in greater than expected proportions by supplementing the fungicides with pruning.

Although certain differences in results will be found between this and the prior report, the main conclusion remains the same. Summer applications of sulphur dusts are the only treatments that have served consistently to prevent new infections of "elm wilt," and the effectiveness of even these treatments is very greatly enhanced by concurrent pruning.

\section{Recommendations}

As previously reported and as stated herein, our results point definitely to summer uso of sulphur dusts for the prevontion of the "clm wilt" discase in 

nursery plantings and indicate strongly that pruning out diseased parts of infected trees is a necessary supplement to the dusts if adequate prevention is to be secured. It has been noticed that healthy nursery elms grow more rapidly if they are treated with a fungicide several times each season. Since both copper sprays and sulphur sprays and dusts stimulate growth, and in this respect repay their cost, quite apart from the disease control they effect, the use of a fungicide is always desirable.

\section{Instructions}

Sulphur dusts should be applied with a power duster, in order to develop a dust fog sufficient to cover all portions of trees being treated. Trees up to 10 feet in height can be treated with a small, hand power duster. However, this is much slower and less satisfactory than a more powerful outfit. It is desirable to dust in earlymorning or just after a light rain, while moisture is still on the foliage and when the air is nearly still. For best results, application of dusts should be made at regular intervals and frequently enough to maintain a complete protective covering on the foliage and wood. The new leaf growth that develops continually throughout the growing season should receive as much protection as possible. In most cases, dusting at two-week intervals during late April, May, and June, when rains are most frequent, and at three-week intervals during July and August will reduce the number of new wilt cases which may occur during any one season and will at the same time give adequate control of leaf spot diseases. 
